\title{
Aconselhamento em Planejamento Reprodutivo de Mulheres em Condições de Vulnerabilidade, segundo a percepção dos profissionais da Estratégia Saúde da Família.
}

Reproductive Planning Counseling of Women in Vulnerability conditions, according to the perception of the professionals of the Family Health Strategy

\author{
Luciana Francisco Lujan * \\ Fernanda Vieira Rodovalho Callegari ** \\ Maristela Carbol ***
}

\begin{abstract}
Resumo:
O presente artigo foi delineado a partir das vivências apreendidas como assistente social do Núcleo de Apoio à Saúde da Família e membro integrante do grupo técnico do planejamento reprodutivo da Secretaria Municipal de Saúde de São Carlos/SP. Fundamenta-se nos resultados da pesquisa de campo realizada junto aos médicos e enfermeiros da Estratégia Saúde da Família deste município, objetivando analisar o aconselhamento em planejamento reprodutivo de mulheres em condições de vulnerabilidade. A partir do material coletado, das deduções realizadas e da perspectiva do referencial teórico, norteado pelos conceitos de vulnerabilidade e clínica ampliada, realizou-se a análise por categorias temáticas. Ao reconhecerem os fatores que produzem vulnerabilidade e que influenciam o processo saúde-doença, os profissionais apontaram ser imprescindível um olhar ampliado no aconselhamento em planejamento reprodutivo dessas mulheres para produzir um cuidado em saúde mais eficaz.
\end{abstract}

Palavras-Chave: Planejamento familiar. Aconselhamento. Vulnerabilidade. Clínica ampliada. Estratégia Saúde da Família.

\begin{abstract}
:
This article was drawn from the experiences learned as a social assistant of the Support Core to Family Health as well as integral member of the technical group in reproductive planning at São Carlos/SP Municipal Secretary of Health. It is based on the results of field research carried out with doctors and nurses from Family Health Strategy of this municipality, objectifying analyzing the reproductive planning counseling of women in vulnerability conditions. From the collected material, of accomplished deductions and theoretical referential perspective, guided by the concepts of vulnerability and extended clinical, accomplished the analysis by thematic categories. By recognizing factors that produce vulnerability and that influences the health-sickness process, the professionals pointed being indispensable an extended look in reproductive planning counseling of this women to produce a more effective health care.
\end{abstract}

Keywords: Family planning. Counseling. Vulnerability. Extended clinic. Family health strategy.

\footnotetext{
* Assistente social da Prefeitura Municipal de São Carlos - SP.

** Professora adjunta do Departamento de Medicina/UFSCar.

*** Docente do Curso de Graduação em Medicina e Pós Graduação em Gestão da Clínica/UFSCar.
} 


\section{Introdução}

A atenção em planejamento familiar é uma temática sempre atual e amplamente discutida nos programas de política de saúde do Brasil (BRASIL, 2016). Na esfera dos direitos sexuais e reprodutivos, a Constituição de 1988 - artigo 226 parágrafo $7^{\circ}$, fundamentou o planejamento familiar da seguinte forma:

\footnotetext{
Fundado nos princípios da dignidade da pessoa humana e da paternidade responsável, o planejamento familiar é livre decisão do casal, competindo ao Estado propiciar recursos educacionais e científicos para o exercício desse direito, vedada qualquer forma coercitiva por parte de instituições oficiais ou privadas (BRASIL, 1988).
}

Em 1996, a Lei no 9.263/96 regulamentou o planejamento familiar no Brasil e, a partir de sua promulgação, o Ministério da Saúde (MS), em conjunto com outras instâncias gestoras da saúde e entidades da sociedade, tem desenvolvido políticas e programas, visando à prevenção e promoção de ações que assegurem a prática de atendimento à saúde sexual e reprodutiva (BRASIL, 1996).

O MS, ao propor o fortalecimento da Atenção Básica (AB) no Brasil, instituiu o Programa de Saúde da Família (PSF), posteriormente chamado de Estratégia Saúde da Família (ESF), como um importante método para reorientação do modelo assistencial (BRASIL, 2012). Entre as diversas áreas de atuação da ESF, a atenção integral à saúde da mulher constitui-se como uma das prioridades no processo de trabalho das equipes de saúde. Desse modo, os programas de prevenção como planejamento reprodutivo e ações relacionadas ao trabalho com população feminina em condições de vulnerabilidade devem ser amplamente conhecidos pelos diversos profissionais da AB (BRASIL, 2011). Para eficácia dessa assistência, conta-se com o trabalho em equipe multiprofissional da ESF e Núcleo de Apoio à Saúde da Família (NASF), considerados importantes pressupostos para reorganização da prática no âmbito da AB (BRASIL, 2010a, 2014a).

A articulação e interação entre os diferentes profissionais da ESF, frente a um contexto sociocultural e econômico complexo e dinâmico, torna-se um relevante instrumento de intervenção, já que as ações se estruturam a partir da equipe (PEREIRA; RIVERA; ARTMANN, 2013). Para análise das situações de saúde, as diferentes condições de vulnerabilidade dos sujeitos individuais e coletivos podem ser particularizadas pelo reconhecimento de três componentes interligados: individual, programática e social. Esses 
três componentes, articulados entre si, tornam-se constitutivos de uma abordagem apoiada no quadro conceitual da vulnerabilidade, que prioriza análises e intervenções multidimensionais e consideram que as pessoas não são, em si, vulneráveis, mas podem estar vulneráveis a alguns agravos e não a outros, sob determinadas condições, em diferentes momentos de suas vidas (AYRES et al., 2011).

O reconhecimento da mulher em condição de vulnerabilidade pelas equipes de saúde pode iniciar a construção de uma proposta de cuidado mais eficaz, de modo que fortaleça a resolubilidade dos problemas dessa população na rede de atenção à saúde (BRASIL, 2011).

São consideradas mulheres em condições de vulnerabilidade as mulheres portadoras de infecção pelo HIV/Aids e outras ISTs, mulheres e adolescentes em situação de violência doméstica e sexual, portadoras de transtornos mentais, mulheres negras, presidiárias, de orientação homossexual, dentre outras (BRASIL, 2013). Nessa direção, a Política Nacional de Atenção Integral à Saúde da Mulher propôs que fossem introduzidas ações mais específicas voltadas a essas populações, em que o planejamento reprodutivo deva ser ofertado de forma integrada por meio de atividades de educação em saúde, atividades clínicas e de aconselhamento, de forma que envolva todos os aspectos da vida e saúde da mulher (BRASIL, 2011; PAIVA et al., 2015). Dentro do planejamento reprodutivo, essas atividades oferecem informações necessárias para a escolha dos métodos contraceptivos mais apropriados à realidade de cada mulher e fomentam reflexões sobre os variados temas relacionados à prática da concepção e anticoncepção (BRASIL, 2013; BEZERRA et al., 2018). No campo da saúde da mulher em condições de vulnerabilidade, as ações de planejamento reprodutivo devem garantir o direito dessas mulheres como de qualquer outra de decidir, de forma livre e responsável, se quer ou não ter filhos, quantos filhos deseja ter e em que momento de sua vida (BRASIL, 2009a).

Para efetivação desse tipo de assistência, os profissionais de saúde precisam se envolver em atividades de aconselhamento que visam orientar as mulheres por meio de um conjunto de ações e atitudes clínicas e práticas em saúde quanto à concepção e métodos contraceptivos reversíveis e irreversíveis disponíveis, de maneira que esclareça a eficácia, efeitos colaterais, vantagens e desvantagens de cada método (BRASIL, 2013).

No âmbito da atuação profissional, o aconselhamento é uma prática preventiva ampla que contribui para promover e elevar a qualidade das ações educativas em saúde e 
pode ser desenvolvido em vários momentos da atenção às mulheres (FALKENBERG et al., 2014). Dessa forma, o aconselhador necessita reavaliar suas atitudes e valores, adquirir habilidade de comunicação e ter conhecimento das características da população que vai atender para fundamentar e direcionar as suas ações de forma coerente e consistente (BARBOSA et al., 2015). Para mulheres em condições de vulnerabilidade, o aconselhamento em planejamento reprodutivo precisa ser ressignificado pelos profissionais de saúde, de forma que o processo educativo se paute em dispositivos de cuidado como comunicação, acolhimento e vínculo; e de arranjos de gestão da clínica ampliada, dentre eles o projeto terapêutico singular e o apoio matricial (BRASIL, 2009b, 2010b). Ao se refletir sobre os diversos significados que as políticas em relação à saúde das mulheres possam trazer, e ainda considerando o Relatório Anual Socioeconômico da Mulher realizado em 2015, em que se observou diferentes aspectos de sua vida, nota-se que ainda temos um caminho a ser percorrido para que de fato todas possam se beneficiar de maneira equitativa dos avanços na área da saúde sexual e reprodutiva (BRASIL, 2015).

Como assistente social do NASF, com atuação em uma das cinco Regionais de Saúde do município de São Carlos-SP, e membro integrante do grupo técnico do planejamento reprodutivo para esterilização cirúrgica da Secretaria Municipal de Saúde do referido município, foi possível aprender nessa vivência profissional as vulnerabilidades e especificidades da população feminina e observar as ações dos profissionais de saúde da $A B$ envolvidos no planejamento reprodutivo.

Com intuito de melhorar a qualidade do cuidado e da organização dos processos de trabalho dos profissionais de saúde da $A B$, e contribuir com reflexões que incentivem a promoção da democracia nas políticas e programas de planejamento reprodutivo, o objetivo do presente artigo consistiu em analisar o aconselhamento em planejamento reprodutivo de mulheres em condições de vulnerabilidade nas unidades de saúde da família, segundo a percepção dos médicos e enfermeiros.

\section{Metodologia}

Trata-se de um estudo exploratório descritivo de abordagem qualitativa. Os participantes desse estudo foram médicos e enfermeiros da ESF das cinco Regionais de Saúde do município de São Carlos/SP, considerados elegíveis aqueles que estavam 
comprometidos com ações na área de atenção à saúde da mulher, atuavam em suas funções há mais de um ano e tinham realizado pelo menos um aconselhamento em planejamento reprodutivo de mulheres em condição de vulnerabilidade no último ano.

O período de coleta de dados ocorreu entre março e junho de 2017, após parecer favorável do Comitê de Ética em Pesquisa e Seres Humanos da Universidade Federal de São Carlos com o número CAAE 62743116.7.0000.5504 e autorização formal dos sujeitos, mediante assinatura do Termo de Consentimento Livre e Esclarecido.

O instrumento utilizado para obtenção dos dados foi uma entrevista semiestruturada aberta com perguntas norteadoras sobre o objeto do estudo. Segundo Minayo (2014), a técnica de entrevista aberta atende aos estudos exploratórios, sendo bastante utilizada quando o pesquisador deseja obter o maior número possível de informações sobre determinado tema, segundo a visão do entrevistado, e também para obter um maior detalhamento do assunto em questão.

As entrevistas foram gravadas individualmente pela própria pesquisadora, transcritas e codificadas com a letra " $E$ " para indicar as falas dos enfermeiros e com a letra " $\mathrm{M}$ " para indicar os médicos, o que garantiu o sigilo de identidade dos participantes.

Para estudo dos dados, foi utilizada a técnica de Análise de Conteúdo Temática descrita por Bardin (2011). Esse método permitiu investigar as vivências dos entrevistados, bem como suas percepções sobre o objeto de estudo. Para a análise, foram percorridas as etapas de pré-análise, descrição analítica e interpretação inferencial.

A partir do material coletado, das deduções realizadas e da perspectiva do referencial teórico, norteados pelos conceitos de vulnerabilidade e clínica ampliada, realizou-se a análise por categorias temáticas.

\section{Resultados e Discussão}

O universo do estudo foi constituído por 26 profissionais, sendo 12 médicos(as) e 14 enfermeiros(as) de um total de 37 profissionais adscritos de 19 territórios no âmbito da ESF.

Diante da leitura flutuante das entrevistas, emergiram duas categorias analíticas: I-Fatores desencadeantes da vulnerabilidade e II-Aconselhamento em planejamento reprodutivo. Essas categorias se desdobraram em 5 subcategorias e 13 unidades de significado que estão apresentadas na tabela 1. 
Tabela 1: Apresentação das categorias, subcategorias e unidades de significado evidenciado no discurso dos participantes do estudo.

\begin{tabular}{lll}
\hline \multicolumn{1}{c}{ CATEGORIAS } & SUBCATEGORIAS & UNIDADES DE SIGNIFICADO \\
\hline $\begin{array}{l}\text { Fatores Desencadeantes } \\
\text { da Vulnerabilidade }\end{array}$ & Fator Socioeconômico & Renda \\
& & $\begin{array}{l}\text { Trabalho } \\
\text { Educação } \\
\text { Moradia }\end{array}$ \\
& Fator Histórico-Cultural & Violência \\
& & Machismo \\
& Fator Político & Políticas Públicas \\
& & \\
\hline $\begin{array}{ll}\text { Aconselhamento em } \\
\text { Planejamento }\end{array}$ & Dispositivos de Cuidado & Acolhimento \\
Reprodutivo & & Escuta \\
& & Linguagem \\
& & Vínculo \\
& & \\
& & Potencialidades \\
& & Fragilidades \\
\hline
\end{tabular}

Fonte: Elaborado pela autora.

\section{Fatores desencadeantes da vulnerabilidade}

Os profissionais de saúde, ao identificar no cotidiano de trabalho as condições de vida e saúde das mulheres, demonstraram que fatores socioeconômico, histórico-cultural e político colocam essas mulheres em posição oposta à que possibilita alcançarem poder para agir, nas dimensões individual e coletiva, limitando sua capacidade de autonomia e, por consequência, seu autocuidado.

\section{Fator Socioeconômico}

A influência da renda no cotidiano das mulheres revelou que a situação financeira não se refere apenas ao fator econômico, mas também aos fatores individuais que envolvem bem-estar, saúde e qualidade de vida. A causalidade entre renda e saúde implica não só na perda da capacidade dessas mulheres em suprir suas necessidades básicas, como reduz os recursos pessoais que interferem no enfrentamento dos agravos. 
[...] são mulheres que estão sem condição financeira, sem uma renda para cumprir com todas as questões de gastos: pagar aluguel ou financiamento de uma casa, comprar comida, comprar remédio, roupa, transporte para acessar aos serviços de saúde e de lazer, enfim, todas as coisas que afetam sua qualidade de vida e de saúde [...]. M7

Alguns relatos evidenciaram que a singularidade de cada mulher que se exprime em sua estrutura econômica e familiar, traz implicações negativas em sua trajetória social, na medida em que se deslocam das condições da vulnerabilidade para a exclusão social. Situações como sobrecarga de atribuições como mãe e dona de casa, com o dever à provisão de dinheiro para a subsistência dela e dos filhos, rompimento de vínculo familiar e o abandono, são vivenciadas como essencialmente desestabilizadores de sua saúde gerando sofrimento psíquico.

[...] seriam as que têm uma baixa renda, que não têm parceiros e tornam-se chefes de família, geralmente sozinhas e com vários filhos - levando uma vida excluída socialmente [...]. E2

O trabalho ocupa lugar de destaque na vida das pessoas por ser fonte geradora de prazer, bem-estar e saúde. Por outro lado, quando realizado sem suporte social, sem reconhecimento, em más condições, pode ser fonte de agravos à saúde por manter relação com a pobreza e com estigmas sociais que tendem a segregar e afastar essas mulheres do convívio com a sociedade.

[...] vejo que são aquelas que estão sempre diante de prejuízos sofridos por trabalho, passam por instabilidades, obtêm baixos rendimentos, sofrem exploração da mão de obra e, por essas razões, são mantidas na pobreza. Então, entendo que essas são situações de vida e de trabalho que as tornam suscetíveis ao agravo de doenças infecciosas [...]. E9

A maioria dos entrevistados enfatizou que a baixa escolaridade traz consequências graves para vida e saúde dessas mulheres, uma vez que a desinformação pode influenciar na autonomia, dificultando tanto a realização de escolhas, como a tomada de decisões, o que reflete na construção do seu autocuidado.

[...] são mulheres que estão mais suscetíveis aos prejuízos na saúde por falta da escolaridade, porque ficam sem autonomia e mais dependentes de outras pessoas para fazer escolhas [...]. E21 
Durante as entrevistas, os participantes identificaram o local e as condições de moradia como geradora de vulnerabilidade e de iniquidade em saúde, o que torna evidente que o território é resultado de uma acumulação de contextos histórico, ambiental e social que promovem condições particulares para a produção de doença.

[...] entendo que são várias situações e motivos que colocam essas mulheres em vulnerabilidade, mas, o que mais me chama atenção, são as desigualdades que elas enfrentam por morarem em condições precárias [...]. E9

Por meio das falas dos participantes, verificou-se que os fatores socioeconômicos desfavoráveis que permeiam as mulheres assistidas por eles são resultantes não apenas de aspectos individuais, mas coletivos e contextuais, que levam ao comprometimento de acesso aos bens e serviços, condições de saúde e qualidade de vida.

As estatísticas do Instituto de Pesquisa Econômica Aplicada (IPEA) revelaram que lares brasileiros chefiados por mulheres saltaram de 23\% para 43\% entre 1995 e 2015.

A equipe do IPEA afirmou que "é elevado o patamar de famílias em que as mulheres não têm cônjuge", o que aumenta "o risco de vulnerabilidade social, já que a renda média das mulheres, especialmente, a das mulheres negras, continua bastante inferior não só à dos homens, como à das mulheres brancas" (IPEA, 2015).

Apesar da persistência e desafios enfrentados com apoio de movimentos feministas na conquista de uma série de políticas econômicas, sociais, educacionais e de saúde, que impulsionaram o avanço das mulheres para garantir seus direitos de forma igualitária e com redução da desigualdade com os homens, Sousa e Guedes (2016) relataram em seu estudo que a divisão sexual do trabalho, o racismo e a classe social ainda estruturam os padrões de desigualdade feminina no Brasil.

Esses autores consideram que as condições sociais não são causas e sim efeitos da opressão socioeconômica às mulheres devido à desigualdade social e de gênero, como àquelas relativas à divisão sexual do trabalho que acabam por gerar sobrecarga e doenças, além da questão da discriminação por gênero e raça que aparece nas diferenças salariais e reconfiguração nos arranjos familiares. Para Silveira e Silva (2013), no nível da organização e da estrutura da sociedade e das transformações no mundo do trabalho, as mulheres sofrem exclusão do sistema produtivo de bens e serviços, e de acordo com a classe social, dentre outras dimensões como gênero, raça/etnia e idade/geração, tendem a vivenciar ainda mais situações de exploração, estigmatização ou destituição dos meios suficientes 
para uma vida digna e plena. Os resultados dessa pesquisa apontaram que as mulheres, ao enfrentar a impossibilidade de acesso aos serviços e direitos básicos de cidadania, como condições habitacionais, educacionais e de trabalho, possuem desvantagens para desfrutar das diferentes oportunidades e qualidade de vida quando comparadas àquelas que possuem tais condições, e nesse sentido, a questão de pertencer a um determinado segmento social mantém relação direta com as desigualdades sociais e vulnerabilidades.

Segundo Massignam, Bastos e Nedel (2015), tais implicações reduzem as oportunidades das mulheres participarem da tomada de decisão favorável a sua autonomia, o que pode gerar autocuidado inadequado e baixa adesão às recomendações do profissional de saúde. Vale ressaltar que uma diversidade de fatores que influenciam a saúde faz com que ela seja reconhecida como produto de um amplo espectro de cuidados relacionados à qualidade de vida, o que inclui um padrão adequado de alimentação e nutrição, habitação e saneamento; boas condições de trabalho; lazer; oportunidades de educação ao longo da vida; ambiente físico e limpo, apoio social para famílias e estilo de vida saudável.

De acordo com Barbosa e Costa (2013), a não garantia de acesso a esses fatores de forma igualitária, coloca as mulheres em situação de vulnerabilidade, gera a vivência de restrições, obstáculos e privações que levam, por sua vez, a caminhos e escolhas, cujo resultado final será a preservação ou agravo da saúde ou a ocorrência das doenças. No contexto social excludente, as iniquidades de oportunidades e de renda contribuem para distribuição desigual e injusta dos fatores materiais, biológicos, psicossociais e comportamentais, os quais são produtores de saúde e qualidade de vida, resultando em distintos perfis epidemiológicos e padrões de acesso aos bens e serviços essenciais à vida. E não é sem razão que os resultados apontados nesta pesquisa retrataram um complexo contexto de vida local e problemas de um território marcado por desigualdades sociais, que sem dúvida impactam em questões de produção de saúde e gestão do cuidado.

\section{Fator Histórico-Cultural}

A violência e o machismo foram observados nos resultados dessa pesquisa como um flagrante desrespeito aos direitos humanos e fundamentais das mulheres, de sorte a impactar severamente no seu desenvolvimento pessoal, social e de saúde. Ao descreverem a desigualdade de gênero nas relações familiares, os entrevistados 
demonstraram que quando os direitos das mulheres são violados e acrescidos a outros determinantes sociais, econômicos e ambientais, elas tornam-se vítimas de violência e acabam por negligenciar os seus próprios cuidados, e passa a vivenciar sofrimentos e enfermidades.

[...] olhando para esse bairro, são aquelas mulheres que tem baixo poder aquisitivo e tem a dependência emocional a um parceiro que é violento, e aí passam a sofrer violência em casa e na rua e isso envolve a comunidade $e$ parentes. Enfim, ficam em condição de vulnerabilidade grave, porque perdem direitos e ficam sem apoio para fazer o enfrentamento da situação [...]. E12

No discurso dos participantes, a manifestação do machismo pode atingir todas as mulheres, mas impacta de forma diferente naquelas que estão mais suscetíveis aos efeitos da vulnerabilidade, por sofrerem com frequência a violência intrafamiliar, relações opressoras e de subordinação-dominação.

[...] eu entendo que todas as mulheres estão em situação de vulnerabilidade na sociedade machista em que eu vivo hoje, mas na área e no local em que eu atuo, percebo que as mulheres que estão em maior vulnerabilidade, são aquelas que, para além do machismo enfrentam a violência econômica e os agravos da falta de escolaridade [...]. M23

A análise das falas dos participantes está evidenciada nos relatos de Oliveira e Fonseca (2014) quando os autores expressam que a partir do momento que se identifica que as atribuições socialmente definidas para homens e mulheres são desiguais e orientadas por questões de gênero, pautadas na hierarquia de poder construída e naturalizada historicamente, a violência contra a mulher se institui dentro da violência de gênero como a mais comum, uma vez que possui certa legitimação social baseada na ideologia machista. De acordo com Costa, Souza e Chagas (2013), esse tipo de violência está presente em toda sociedade e é reflexo de um histórico processo de desrespeito e violação dos direitos mais elementares como direito à vida, liberdade e disposição do corpo, assim como exclusão que o gênero feminino tem enfrentado ao longo dos anos.

No sentido de identificar situações de violência que comprometam a condição de vida e saúde das mulheres, alguns entrevistados evidenciaram violência intrafamiliar, violência doméstica e violência econômica como formas de violação de direitos humanos, que as impedem de fazer o enfrentamento das situações, ficando em condições de vulnerabilidade grave. 
Para autores como Menezes et al. (2014) e Rodrigues et al. (2014), é imprescindível que os profissionais, independente do espaço de atuação, estejam aptos para identificar mulheres em vivência de violência e as implicações que acarretam no processo saúde-doença, assim como possam ter condições de acolhimento e escuta para atuarem de forma sensível e eficaz, e contribuir para o fortalecimento de uma vida autônoma e livre de violência. O discurso dos participantes quanto ao cuidado compartilhado dessas mulheres em situação de violência foi de encontro ao de Arboit et al. (2017) e Holanda et al. (2017) que referem que, para garantir à mulher atendimento as suas necessidades é necessário que a prevenção e o enfrentamento da violência ocorram por interlocução dos diversos serviços de atenção: jurídico, policial, social, de geração de renda, de habitação e educação; e da atuação do governo e das instituições que as assistem por meio de ações políticas, sociais e econômicas, e de toda a sociedade, dada a complexidade que envolve os contextos de violência.

Não há dúvidas de que discutir violência é reconhecer sua complexidade como um fenômeno que se transforma à medida que valores e normas sociais assumem novos significados por influência do contexto histórico-cultural, já que o problema que leva tantas mulheres a sofrerem os mais diversos tipos de violência diz menos respeito ao seu comportamento e mais às raízes da estrutura social em que se vive.

\section{Fator Político}

O depoimento dos participantes frente ao fator político traz à tona o compromisso das políticas públicas com ações integradas e intersetoriais na composição das redes de atenção à saúde, que proporcionem bem-estar físico, mental e social àqueles que vivem nos territórios de maior vulnerabilidade.

[...] na maioria das vezes para conseguir ter maior resolubilidade nos atendimentos com essas mulheres, para fazer o enfrentamento de suas fragilidades, contamos com a equipe, CEME [Centro Municipal de Especialidades Médicas], CAPS [Centro de Atenção Psicossocial], CAIC [Centro de Atendimento de Infeç̧ões Crônicas], CRAS [Centro de Referência de Assistência Social.]. Enfim, a gente se integra com profissionais que atendem em outros lugares, para ofertar cuidado a essas pessoas que vivem em vulnerabilidade. Então, a gente percebe que sem investimento público essas pessoas não tem como ter o mínimo de apoio para viver. Esse trabalho integrado com a rede intersetorial traz ganho para essa população na parte social, psicológica e física [...]. M5 
A análise dos discursos dos participantes mostrou que o trabalho integrado com a rede intersetorial salvaguarda integralidade do cuidado às mulheres, e em razão da complexidade que permeia o seu contexto de vida com vulnerabilidades, o investimento de recursos públicos são essenciais para construir redes de atenção para enfrentamento dos problemas que envolvem as causas estruturais inerentes aos aspectos socioeconômicos, culturais, políticos e de saúde. Nesse contexto, Custódio e Silva (2015) consideram que não se pode pensar em efetivação de políticas públicas sem levar em conta a relevância da interação e integração dos diversos órgãos, instituições e daqueles que se encontram inseridos no compromisso comum da efetivação dos direitos sociais. $A$ intersetorialidade é uma importante ferramenta para garantir a legitimidade das políticas públicas e servir como meio de trabalho no âmbito da saúde.

Segundo Malta et al. (2014), a ampliação das ações por meio da intersetorialidade significa garantir oportunidade de escolhas que sejam mais favoráveis a todos e os tornem protagonistas no processo de produção da saúde e melhoria de sua qualidade de vida, no aspecto biopsicossocial. Evidencia-se, pelas falas dos entrevistados, que as políticas públicas precisam assegurar investimentos e distribuir recursos com vistas a atingir o desenvolvimento social nos territórios, além de possibilitar que as mulheres desfrutem de melhoria na qualidade de vida e da sua saúde.

Nesse sentido, Salvador e Yannoulas (2013) relataram que para as políticas públicas serem concretizadas de maneira eficiente e contribuam para a redução das desigualdades sociais e em defesa da vida, é extremamente necessária a construção de uma cultura reflexiva junto à população sobre suas finalidades e prioridades, com discussões que envolvam o orçamento público, enquanto instrumento estratégico para concretização dos direitos sociais e para exercício do controle social. De acordo com as falas dos participantes cuja destinação de recursos deve ser direcionada aos problemas que afligem a população, Custódio e Silva (2015) também consideram assim quando relatam em seu estudo que as políticas públicas devem ser estabelecidas de maneira compartilhada por iniciativa dos representantes políticos no exercício de suas funções, dos trabalhadores e da população, com vistas à efetivação do exercício pleno da cidadania. As políticas atuais destacam proposições relativas à promoção da saúde no âmbito da ESF que oferece uma nova visão de organização dos processos de trabalho para intervir na prestação dos cuidados em saúde e reestruturar o modelo de $A B$. 


\section{Aconselhamento em Planejamento Reprodutivo}

Com base no discurso dos entrevistados, constatou-se que para realizar o aconselhamento em planejamento reprodutivo de mulheres em condições de vulnerabilidade, é necessário um olhar ampliado na produção do cuidado em saúde devido à singularidade e a coletividade que as envolve. Ainda, evidenciou-se nessas falas a utilização de dispositivos de cuidado e a inclusão de novos instrumentos no processo de trabalho para a organização do cuidado dessas mulheres. Dispositivos de Cuidado Ao considerar as políticas de direitos sexuais e reprodutivos desenvolvidas na ESF, os profissionais entrevistados colocaram o cuidado em saúde como uma diretriz para atender as mulheres, utilizando-se de diversos dispositivos assistenciais como acolhimento, escuta, linguagem e vínculo para viabilizar o aconselhamento em planejamento reprodutivo.

[...] em qualquer atendimento que faço é sempre acolhendo o que elas precisam e tentando fazer as informações sobre o planejamento familiar, mas sem dúvida, quando eu me deparo com uma mulher como as usuárias de álcool e drogas, desenvolvo uma escuta mais pacienciosa, até para entender o que as trouxe na unidade. Às vezes é necessário incluir outros profissionais de saúde para dar suporte. Assim, tem que estar atento nesse primeiro momento, porque é mais ouvir do que falar, caso contrário, a gente não estabelece laços de confiança e menos ainda o cuidado de que precisam na saúde [...]. E10

Os participantes enfatizaram a importância da postura do acolhedor, atento ao cuidado com a linguagem no aconselhamento, de forma que possam confiar nos profissionais de saúde e consigam de fato realizar suas escolhas.

[...] às vezes o olhar, o gesto que você faz no momento do aconselhamento diz muita coisa. Então, a linguagem não verbal é muito importante na hora de uma conversa, às vezes você não julga com palavras, mas o seu olhar de preconceito, aquele olhar de criminalização, já deixa a pessoa na defensiva e nada se constrói [...]. E16

Ficou ressaltado pela maioria dos profissionais que são necessários vários acolhimentos para a produção de vínculo e isso exige que se utilize de relações mais integradoras, que gerem afetos para o seguimento do cuidado com vistas à autonomia dessas usuárias. 
[...] eu tenho algumas dificuldades para realizar o aconselhamento contraceptivo com essas mulheres, porque isso se dá em várias etapas, é a questão da abordagem. De primeiro momento se você vier logo com o receituário, para fazer a indicação do contraceptivo, você não vai conseguir. Então, às vezes eu marco uma consulta, passa uma semana eu marco outra, vou conversando $e$ ouvindo. Tento identificar o que está pegando pelo fato de ela não estar usando, e qual vai ser a forma que eu vou intervir para tentar com que ela tenha independência no seu tratamento [...]. E15

De acordo com alguns autores, o cuidado não pode se restringir apenas às competências e tarefas técnicas, pois acolhimento, escuta, linguagem e vínculo são recursos inerentes à sua constituição e devem permear as práticas de saúde com foco na integralidade e na humanização em qualquer momento da interação entre os profissionais, equipe e as usuárias (PINHEIRO, 2008; LOPES et al., 2015; KALICHMAN; AYRES, 2016).

Nesse processo de produção do cuidado, um achado relevante no discurso dos entrevistados foi a referência da postura do aconselhador: isenta de julgamentos e preconceitos. Conforme publicação no Caderno de Saúde Sexual e Reprodutiva, atitudes preconceituosas e de julgamento estimulam as disparidades e iniquidades e impactam negativamente no acesso e permanência das usuárias no sistema de saúde, o que configura como um cuidado não integral (BRASIL, 2013). Nas entrevistas, foi possível perceber que devido à pluralidade das demandas no campo da vida sexual e reprodutiva, os profissionais utilizaram os dispositivos de cuidado de maneira mais sistematizada nas mulheres em condições de vulnerabilidade, provavelmente, em virtude do contexto desfavorável que as prejudicam e afetam o seu contato com os serviços de saúde.

A implementação de espaços coletivos de discussão sobre saúde sexual e reprodutiva potencializa enfrentamentos às problemáticas que envolvem a saúde da mulher com ou sem vulnerabilidades e horizontalidade nas decisões. Segundo o Manual de Educação Popular em Saúde, as atividades de educação em saúde são estratégias eficientes para permear um aconselhamento que promova autonomia às pessoas. E para isso, é necessário que as ações educativas sejam contínuas e ofertadas às mulheres, aos homens e aos casais, independente das condições de vulnerabilidade (BRASIL, 2014b).

Essa ideia possibilita gerar novas iniciativas de cuidado e resolução das dificuldades enfrentadas pelas mulheres na concepção e contracepção e do seu empoderamento diante das implicações nas relações familiares e de gênero para que possam ter autonomia e fazer escolhas conscientes frente à sua vida sexual e reprodutiva. 


\section{Processo de Trabalho}

Diante das dimensões sociais, emocionais e culturais presentes no cotidiano de trabalho dos profissionais, foi possível verificar que eles também utilizam os recursos da clínica ampliada, como Equipe de Referência (ER) e Equipe de Apoio Matricial (EAM), para operacionalizar o aconselhamento de mulheres em condições de vulnerabilidade.

[...] muitas vezes, essas mulheres precisam do olhar de todos os setores, seja a enfermagem, o médico, os profissionais do Núcleo de Apoio à Saúde da Família, o agente comunitário de saúde. A gente tem que levar o caso para essa equipe. Discutir com esses profissionais a história de vida, e o contexto que a mulher vive, para tentar aos poucos incluí-la no planejamento familiar [...]. E4

Os participantes comentaram que o Projeto Terapêutico Singular (PTS) tem sido uma ferramenta de trabalho muito útil nesses casos e que a Rede de Apoio tem sido de extrema valia para o cuidado compartilhado.

[...] a gente discute, estuda o caso, divide o que pode ficar sob atenção de cada um, e para isso, fazemos o projeto terapêutico. Assim, acabamos de alguma forma tendo um olhar a mais, identificando alguém que possa fazer parte desse projeto para além da paciente: a família, amigos, vizinhos, alguém que nos ajude a potencializar essa questão de prevenção para essa usuária [...]. M13

As proposições da clínica ampliada visam tratar as pessoas de maneira integral e buscar a produção de saúde, reabilitação e ampliação da autonomia, por meio da construção de vínculo, integração da equipe multiprofissional, corresponsabilização dos usuários, compartilhamento de diagnóstico e cuidado terapêutico, além da elaboração do PTS (BRASIL, 2009b). A reorientação do modo de operar o processo de trabalho com dispositivos estratégicos como ER, EAM e PTS é fundamental para ampliar a participação e a autonomia das usuárias e concretizar a humanização no modelo de atenção e gestão do cuidado (KALICHMAN; AYRES, 2016).

Segundo Gehling (2014), trata-se de um trabalho clínico que compreende o sujeito em suas diferenças e particularidades, além de considerar o contexto de sua vida, história, subjetividade, família e território, incluindo não apenas a produção de saúde, mas também ampliando a sua autonomia. Fica evidente para esse autor a importância da atuação de uma equipe multidisciplinar munida de um planejamento em saúde norteada 
por estratégias que podem ser desenvolvidas por todos os membros da equipe. Tais estratégias devem ser planejadas a partir do enfoque da educação em saúde e do trabalho coletivo, com o propósito de prevenção de agravos e promoção da saúde sexual para melhorar a qualidade de vida e saúde das pessoas.

A abordagem ampliada da atenção à saúde na ESF faz emergir a problematização no processo de trabalho, que por ser em parte fruto da subjetividade humana e da complexa realidade adscrita ao território, pode trazer aos profissionais de saúde dificuldades no cumprimento dos seus papéis de educadores em saúde (BARBOSA et al., 2015; BEDRIKOW; CAMPOS, 2017).

Pensar no aconselhamento em planejamento reprodutivo para mulheres em condições de vulnerabilidade significa ampliar e qualificar as ações sem estereotipar o feminino, mas considerar que pertencem a um grupo passível de fragilidades e vitimizações, de forma que as diretrizes estabelecidas para o trabalho em saúde deva atingir a perspectiva da integralidade da atenção e da equidade no sistema de saúde com reconhecimento das reais necessidades de cada mulher no seu contexto de vida.

\section{Considerações Finais}

A pesquisa constatou que os fatores socioeconômico, histórico-cultural e político foram identificados como desencadeantes da vulnerabilidade das mulheres pertencentes aos territórios das USF do município de São Carlos, e que eles contribuem para a perpetuação dos ciclos de pobreza e exclusão social, além de formar barreiras que afetam de maneira desigual as oportunidades e possibilidades dessas mulheres desenvolverem uma vida saudável. Uma vez que esses fatores estão presentes no cotidiano de vida dessas mulheres, estas desenvolvem uma dinâmica de privação por falta de acesso aos sistemas sociais básicos, que as tornam mais suscetíveis ao enfrentamento da violência, as questões de gênero e aos agravos à sua saúde física e psíquica, o que reduz sua capacidade de decisão e ação.

O reconhecimento das vulnerabilidades que afetam a saúde das mulheres mobiliza os profissionais de saúde a conduzir o aconselhamento em planejamento reprodutivo, considerando a complexidade e a singularidade de cada situação apresentada nos territórios das USF. Os dispositivos assistenciais de cuidado como acolhimento, escuta, linguagem e vínculo têm sido utilizados de forma sistematizada para 
favorecer abordagens integradas e assegurar o cuidado longitudinal em saúde sexual e reprodutiva de mulheres em condições de vulnerabilidade.

A dinâmica do processo de trabalho, ao utilizar recursos da clínica ampliada, demonstrou ser estratégia valiosa e desafiadora para ampliar as possibilidades de eficácia na escolha e utilização dos métodos contraceptivos entre essas mulheres. Como ferramenta de gestão, a EPS deve ser incentivada, pois valoriza positivamente os profissionais, fortalece a equipe de saúde e facilita o aconselhamento em planejamento reprodutivo. Intervenções de políticas públicas capazes de reduzir as iniquidades com ações programadas nos territórios e consolidação dos processos democráticos foram evidenciadas como necessidades prementes. Além disso, ficou registrado que maior investimento do gestor público na mobilização de recursos comunitário, institucional e intersetorial são essenciais para melhoria da qualidade e equidade da atenção à saúde e do acesso dessas mulheres nas USF.

Realizar planejamento reprodutivo de mulheres em condições de vulnerabilidade sob os princípios da integralidade requer atenção especial, pois a complexidade e a singularidade que as envolvem, ao mesmo tempo em que proporcionam aos profissionais de saúde a utilização de diferentes estratégias e recursos para um adequado aconselhamento, geram inseguranças e sentimentos conflituosos que podem comprometer o cuidado.

Enfim, fortalecer a gestão do cuidado e do processo de trabalho na saúde sexual e reprodutiva de mulheres em condições de vulnerabilidade contribui para garantir os seus direitos na sociedade e ajuda no estado de completo bem-estar social, mental e físico para que possam melhorar sua qualidade de vida. Concluiu-se que os médicos e enfermeiros da ESF identificaram que mulheres em condições de vulnerabilidade vivenciam de maneira desigual e em desvantagem os fatores socioeconômico, históricocultural e político. Além disso, os profissionais têm utilizado dispositivos e arranjos de gestão do cuidado e da clínica ampliada para realizar o aconselhamento em planejamento reprodutivo dessas mulheres.

\section{Referências}

ARBOIT, J.; PADOIN, S. M. M.; VIEIRA, L. B.; PAULA, C. C.; COSTA, M. C.; CORTES, L. F. Atenção à saúde de mulheres em situação de violência: desarticulação dos profissionais em rede. Revista da Escola de Enfermagem da USP, São Paulo, v. 51, n. 3, p. 1-7, 2017. 
Disponível em: http://www.scielo.br/pdf/reeusp/v51/pt_1980-220X-reeusp-51e03207.pdf. Acesso em: 15 maio 2018.

AYRES, J. R. C. M.; FRANÇA JÚNIOR, I.; CALAZANS, G. J.; SALETTI FILHO, H. C. O conceito de vulnerabilidade e as práticas de saúde: novas perspectivas e desafios. In: CZERESNIA, D.; FREITAS, C. M. (org.). Promoção da saúde: conceitos, reflexões, tendências. 2. ed. Rio de Janeiro: Fiocruz, 2011. p. 117-139.

BARBOSA, I. R.; COSTA, I. C. C. A determinação social no processo de adoecimento no contexto das populações negligenciadas. In: PORTAL DSS-NORDESTE. Recife, 27 mar. 2013. Disponível em: http://dssbr.org/site/opinioes/a-determinacao-social-no- processo-deadoecimento-no-contexto-das-populacoes-negligenciadas. Acesso em: 10 nov. 2017.

BARBOSA, T. L. A.; GOMES, L. M. X.; HOLZMANN, A. P. F.; PAULA, A. M. B.; HAIKAL, D. S. A. Aconselhamento em doenças sexualmente transmissíveis na atenção primária: percepção e prática profissional. Acta Paulista de Enfermagem, São Paulo, v. 28, n. 6, p. 531-538, 2015. Disponível em: http://www.scielo.br/pdf/ape/v28n6/1982-0194-ape-28-060531.pdf. Acesso em: 15 fev. 2017.

BARDIN, L. Análise de conteúdo. São Paulo: Edições 70, 2011.

BEDRIKOW, R.; CAMPOS, G. W. S. A clínica nos documentos para a Atenção Básica no Brasil. Espaço para a Saúde: Revista de Saúde Pública do Paraná, Londrina, v. 18, n. 2, p. 25-35, dez. 2017. Disponível em:

http://espacoparasaude.fpp.edu.br/index.php/espacosaude/article/view/234/pdf_1. Acesso em: 27 abr. 2018.

BEZERRA, E. J.; ALMEIDA, T. S. C.; PASSOS, N. C. R.; PAZ, C. T.; BORGES-PALUCH, L. R. Planejamento reprodutivo na estratégia saúde da família: estudo qualitativo sobre a dinâmica do atendimento e os desafios do programa. Arquivos de Ciências da Saúde da UNIPAR, Umuarama, v. 22, n. 2, p. 99-108, maio/ago. 2018. Disponível em: http://revistas.unipar.br/index.php/saude/article/view/6349/3570. Acesso em: 25 jun. 2018.

BRASIL. [Constituição (1988)]. Constituição da República Federativa do Brasil de 1988. Brasília: Presidência da República, 1988. Disponível em: http://www.planalto.gov.br/ccivil_03/constituicao/constituicao.htm. Acesso em: 7 dez. 2016.

BRASIL. Lei no 9.263, de 12 de janeiro de 1996. Regula o § 70 do art. 226 da Constituição Federal, que trata do planejamento familiar, estabelece penalidades e dá outras providências. Brasília: Presidência da República, 1996. Disponível em: http://www.planalto.gov.br/ccivil_03/leis/I9263.htm. Acesso em: 25 fev. 2017.

BRASIL. Ministério da Saúde. Instituto Sírio-Libanês de Ensino e Pesquisa. Protocolos da Atenção Básica: saúde das mulheres. Brasília: Ministério da Saúde, 2016. Disponível em: http://189.28.128.100/dab/docs/portaldab/publicacoes/protocolo_saude_mulher.pdf. Acesso em: 22 set. 2017. 
BRASIL. Ministério da Saúde. Secretaria de Atenção à Saúde. Departamento de Ações Programáticas Estratégicas. Direitos sexuais, direitos reprodutivos e métodos anticoncepcionais. Brasília: Ministério da Saúde, 2009a.

BRASIL. Ministério da Saúde. Secretaria de Atenção à Saúde. Departamento de Atenção Básica. Diretrizes do NASF: Núcleo de Apoio à Saúde da Família. Brasília: Ministério da Saúde, 2010a. (Cadernos de Atenção Básica, n. 27).

BRASIL. Ministério da Saúde. Secretaria de Atenção à Saúde. Departamento de Ações Programáticas Estratégicas. Política Nacional de Atenção Integral à Saúde da Mulher: princípios e diretrizes. Brasília: Ministério da Saúde, 2011.

BRASIL. Ministério da Saúde. Secretaria de Atenção à Saúde. Departamento de Atenção Básica. Política Nacional de Atenção Básica. Brasília: Ministério da Saúde, 2012. (Série E. Legislação em Saúde). Disponível em:

http://189.28.128.100/dab/docs/publicacoes/geral/pnab.pdf. Acesso em: 15 mar. 2018.

BRASIL. Ministério da Saúde. Secretaria de Atenção à Saúde. Departamento de Atenção Básica. Saúde sexual e saúde reprodutiva. Brasília: Ministério da Saúde, 2013. (Cadernos de Atenção Básica, n. 26). Disponível em:

http://bvsms.saude.gov.br/bvs/publicacoes/saude_sexual_saude_reprodutiva.pdf. Acesso em: 22 nov. 2016.

BRASIL. Ministério da Saúde. Secretaria de Atenção à Saúde. Departamento de Atenção Básica. Núcleo de Apoio à Saúde da Família. Brasília: Ministério da Saúde, 2014a. (Cadernos de Atenção Básica, n. 39). Disponível em: http://bvsms.saude.gov.br/bvs/publicacoes/nucleo_apoio_saude_familia_cab39.pdf. Acesso em: 10 out. 2018.

BRASIL. Ministério da Saúde. Secretaria de Atenção à Saúde. Núcleo Técnico da Política Nacional de Humanização. Acolhimento nas práticas de produção de saúde. Brasília: Ministério da Saúde, 2010b. (Série B. Textos Básicos de Saúde).

BRASIL. Ministério da Saúde. Secretaria de Atenção à Saúde. Política Nacional de Humanização da Atenção e Gestão do SUS. Clínica ampliada e compartilhada. Brasília: Ministério da Saúde, 2009b. (Série B. Textos Básicos de Saúde).

BRASIL. Ministério da Saúde. Secretaria de Gestão Estratégica Participativa. /l Caderno de educação popular em saúde. Brasília: Ministério da Saúde, 2014b. Disponível em: http://bvsms.saude.gov.br/bvs/publicacoes/2_caderno_educacao_popular_saude.pdf. Acesso em: 17 set. 2018

BRASIL. Presidência da República. Secretaria de Políticas para as Mulheres. Relatório Anual Socioeconômico da Mulher. Brasília: Secretaria de Políticas para as Mulheres, 2015. Disponível em: http://www.biblioteca.presidencia.gov.br/publicacoesoficiais/catalogo/dilma/spm_livro-relatorio-anual-socioeconomico-damulher_2015.pdf/view. Acesso em: 14 jun. 2017.

COSTA, A. S.; SOUZA, J. M. P. E.; CHAGAS, M. C. Convenção interamericana para prevenir, punir e erradicar a violência contra a mulher: convenção de Belém do Pará. In: LOPES, A. 
M. D.; JUCÁ, R. L. C; COSTA, A. S. (org.). Gênero e tráfico de mulheres. Florianópolis: Conceito Editorial, 2013. p. 147-154. Disponível em:

https://www.academia.edu/34793563/G\%C3\%8ANERO_E_TR\%C3\%81FICO_DE_MULHERE S. Acesso em: 24 jan. 2018.

CUSTÓDIO, A.; SILVA, C. R. C. A intersetorialidade nas políticas sociais públicas. In: SEMINÁRIO NACIONAL DEMANDAS SOCIAIS E POLÍTICAS PÚBLICAS NA SOCIEDADE CONTEMPORÂNEA, 11., 2015, Santa Cruz do Sul. Anais [...]. Santa Cruz do Sul: UNISC, 2015. p. 2-18. Disponível em:

https://online.unisc.br/acadnet/anais/index.php/snpp/article/viewFile/14264/2708. Acesso em: 13 maio 2018.

FALKENBERG, M. B.; MENDES, T. P. L.; MORAES, E. P.; SOUZA, E. M. Educação em saúde e educação na saúde: conceitos e implicações para a saúde coletiva. Ciência \&. Saúde Coletiva, Rio de Janeiro, v. 19, n. 3, p. 847-852, 2014. Disponível em:

http://www.scielo.br/pdf/csc/v19n3/1413-8123-csc-19-03-00847.pdf. Acesso em: 18 mar. 2018.

GEHLING, C. R. Planejamento familiar e a possibilidade de atuação na realidade através do trabalho em equipe multiprofissional. 2014. $30 \mathrm{f}$. Trabalho de conclusão (Mestrado profissional em Ensino na Saúde) - Universidade Federal do Rio Grande do Sul, Porto Alegre, 2014.

HOLANDA, E. R.; HOLANDA, V. R.; VASCONCELOS, M. S.; SOUZA, V. P.; GALVÃO, M. T. G. Fatores associados à violência contra as mulheres na atenção primária de saúde. Revista Brasileira em Promoção da Saúde, Fortaleza, v. 31, n. 1, p. 1-9, 2017. Disponível em: https://periodicos.unifor.br/RBPS/article/view/6580/pdf. Acesso em: 1 maio 2018.

IPEA - INSTITUTO DE PESQUISA ECONÔMICA APLICADA. Retrato das desigualdades de gênero e raça. Brasília: IPEA, 2015. Disponível em:

http://www.ipea.gov.br/retrato/index.html. Acesso em: 15 mar. 2017.

KALICHMAN, A. O.; AYRES, J. R. C. M. Integralidade e tecnologias de atenção à saúde: uma narrativa sobre contribuições conceituais à construção do princípio da integralidade no SUS. Cadernos de Saúde Pública, Rio de Janeiro, v. 32, n. 8, p. 1-13, 2016. Disponível em: http://www.scielo.br/pdf/csp/v32n8/1678-4464-csp-32-08-e00183415.pdf. Acesso em: 25 jun. 2018.

LOPES, A. S.; VILAR, R. L. A.; MELO, R. H. V.; FRANÇA, R. C. S. O acolhimento na Atenção Básica em saúde: relações de reciprocidade entre trabalhadores e usuários. Saúde em Debate, Rio de Janeiro, v. 39, n. 104, p. 114-123, jan./mar. 2015. Disponível em: http://www.scielo.br/pdf/sdeb/v39n104/0103-1104-sdeb-39-104-00114.pdf. Acesso em: 26 jun. 2018.

MALTA, D. C.; SILVA, M. M. A.; AlBUQUeRQUE, G. M.; LIMA, C. M.; CAVAlCANTE, T.; JAIME, P. C.; SILVA JÚNIOR, J. B. A implantação das prioridades da Política Nacional de Promoção da Saúde, um balanço, 2006 a 2014. Ciência \&. Saúde Coletiva, Rio de Janeiro, v. 19, n. 11, p. 4301-4311, 2014. Disponível em: http://www.scielo.br/pdf/csc/v19n11/1413-8123-csc-19-11-4301.pdf. Acesso em: 6 maio 2018. 
MASSIGNAM, F. M.; BASTOS, J. L. D.; NEDEL, F. B. Discriminação e saúde: um problema de acesso. Epidemiologia e Serviços de Saúde, Brasília, v. 24, n. 3, p. 541-544, 2015.

Disponível em: http://scielo.iec.gov.br/pdf/ess/v24n3/v24n3a20.pdf. Acesso em: 19 ago. 2017.

MENEZES, P. R. M.; LIMA, I. S.; CORREIA, C. M.; SOUZA, S. S.; ERDMANN, A. L.; GOMES, N. $P$. Enfrentamento da violência contra a mulher: articulação intersetorial e atenção integral. Saúde e Sociedade, São Paulo, v. 23, n. 3, p. 778-786, 2014. Disponível em: http://www.scielo.br/pdf/sausoc/v23n3/0104-1290-sausoc-23-3-0778.pdf. Acesso em: 22 abr. 2018.

MINAYO, M. C. S. O desafio do conhecimento: pesquisa qualitativa em saúde. 10. ed. São Paulo: Hucitec, 2014.

OLIVEIRA, R. N. G.; FONSECA, R. M. G. S. A violência como objeto de pesquisa e intervenção no campo da saúde: uma análise a partir da produção do grupo de pesquisa Gênero, Saúde e Enfermagem. Revista da Escola de Enfermagem da USP, São Paulo, v. 48, n. esp. 2, p. 32-39, 2014. Disponível em:

http://www.scielo.br/pdf/reeusp/v48nspe2/pt_0080-6234-reeusp-48-nspe2-00031.pdf. Acesso em: 1 abr. 2018.

PAIVA, C. C. N.; VILLAR, A. S. E.; SOUZA, M. D.; LEMOS, A. Educação em saúde segundo os preceitos do movimento feminista: estratégias inovadoras para promoção da saúde sexual e reprodutiva. Escola Anna Nery, Rio de Janeiro, v. 19, n. 4, p. 685-691, out./dez. 2015. Disponível em: http://www.scielo.br/pdf/ean/v19n4/1414-8145-ean-19-04-0685.pdf. Acesso em: 19 abr. 2018.

PEREIRA, R. C. A.; RIVERA, F. J. U.; ARTMANN, E. O trabalho multiprofissional na Estratégia Saúde da Família: estudo sobre modalidades de equipes. Interface: Comunicação, Saúde, Educação, Botucatu, v. 17, n. 45, p. 327-340, abr./jun. 2013. Disponível em: http://www.scielo.br/pdf/icse/v17n45/aop0613.pdf. Acesso em: 15 out. 2018.

PINHEIRO, R. Cuidado em Saúde. In: PEREIRA, I. B.; LIMA, J. C. F. (org.). Dicionário da educação profissional em Saúde. Rio de Janeiro: EPSJV, 2008. p. 110-114. Disponível em: http://www.sites.epsjv.fiocruz.br/dicionario/Dicionario2.pdf. Acesso em: 2 jun. 2018.

RODRIGUES, V. P.; MACHADO, J. C.; SIMÕES, A. V.; PIRES, V. M. M. M.; PAIVA, M. S.; DINIZ, N. M. F. Práticas de trabalhadora(e)s de saúde na atenção às mulheres em situação de violência de gênero. Texto \& Contexto: Enfermagem, Florianópolis, v. 23, n. 3, p. 735-743, jul./set. 2014. Disponível em: http://www.scielo.br/pdf/tce/v23n3/pt_0104-0707-tce-2303-00735.pdf. Acesso em: 26 maio 2017.

SALVADOR, E. S.; YANNOULAS, S. C. Orçamento e financiamento de políticas públicas: questões de gênero e raça. Revista Feminismos, Salvador, v. 1, n. 2, p. 1-27, 2013. Disponível em: https://portalseer.ufba.br/index.php/feminismos/article/view/29937/17702. Acesso em: 21 mar. 2018. 
SILVEIRA, E. C.; SILVA, S. F. M. Chefia feminina: uma análise sobre a estrutura das famílias monoparentais femininas e a feminização da pobreza. In: SEMINÁRIO CETROS, 4., 2013, Fortaleza. Anais [...]. Fortaleza: UECE, 2013. p. 122-137. Disponível em:

http://www.uece.br/eventos/seminariocetros/anais/trabalhos_completos/69-1723808072013-162104.pdf. Acesso em: 12 ago. 2018.

SOUSA, L. P.; GUEDES, D. R. A desigual divisão sexual do trabalho: um olhar sobre a última década. Estudos Avançados, São Paulo, v. 30, n. 87, p. 123-138, 2016. Disponível em: http://www.scielo.br/pdf/ea/v30n87/0103-4014-ea-30-87-00123.pdf. Acesso em: 20 jun. 2018. 